\title{
Time-varying return predictability and adaptive markets hypothesis: Evidence on MIST countries from a novel wild bootstrap likelihood ratio approach
}

\author{
Oktay ÖZKAN* \\ Tokat Gaziosmanpaşa University
}

\begin{abstract}
This paper investigates the evolution of the return predictability (or market efficiency) degree for Mexico, Indonesia, South Korea, and Turkey (MIST) countries and examines whether the findings are consistent with the implications of adaptive markets hypothesis (AMH). For this purpose, the novel wild bootstrap likelihood ratio approach of Kim and Shamsuddin (2020) is applied on the monthly data from January 1993 to July 2020 with the rolling sub-sample windows method to determine whether the ability of inflation and trading volume to predict stock market returns varies over time. The empirical findings verify that the return predictability (or market efficiency) is time-varying consistent with the implications of the AMH for all MIST countries. This verification is also strengthened by using other predictor variables, namely, exchange rate and realized volatility. This paper reveals that the AMH is more successful in explaining real stock market behavior than efficient markets hypothesis.
\end{abstract}

Keywords: Adaptive markets hypothesis, efficient markets hypothesis, market efficiency, return predictability, wild bootstrap likelihood ratio test, MIST, rolling sub-sample windows

Jel Classification: C22, G11, G14.

Zamanla değişen getiri öngörülebilirliği ve adaptif piyasalar hipotezi: Yeni bir yaklaşım olan wild bootstrap olabilirlik oranı ile MIST ülkeleri üzerinden kanitlar

\section{Özet}

$\mathrm{Bu}$ çalışma Meksika, Endonezya, Güney Kore ve Türkiye (MIST) ülkeleri için getiri öngörülebilirliği (veya piyasa etkinliği) derecesinin değişimini araştırmakta ve elde edilen bulguların adaptif piyasalar hipotezi (AMH) ile uyumlu olup olmadığını incelemektedir. Bu amaç için, enflasyon ve işlem hacminin borsa getirilerini tahmin etme yeteneğinin zaman içinde değişim gösterip göstermediğini belirlemek için Ocak 1993'ten Temmuz 2020'ye kadar olan aylık veriler üzerinde Kim ve Shamsuddin (2020)'in wild bootstrap olabilirlik oranı yaklaşımı hareketli alt örneklem pencereleri yöntemi ile uygulanmıştır. Ampirik bulgular, getiri öngörülebilirliğinin (veya piyasa etkinliğinin) tüm MIST ülkeleri için AMH ile uyumlu bir şekilde zamana göre değiştiğini doğrulamaktadır. Bu doğrulama döviz kuru ve gerçekleşen oynaklık şeklindeki tahmin değişkenleri kullanılarak da güçlendirilmiştir. $\mathrm{Bu}$ çalışma, AMH'nin gerçek borsa davranışını açıklamada etkin piyasalar hipotezinden daha başarılı olduğunu ortaya koymaktadır.

Anahtar Kelimeler: Adaptif piyasalar hipotezi, etkin piyasalar hipotezi, piyasa etkinliği, getiri öngörülebilirliği, wild bootstrap olabilirlik oranı testi, MIST, hareketli alt örneklem pencereleri

JEL Sinıflandırması: C22, G11, G14.

\footnotetext{
* Oktay Özkan. Research Assistant, Tokat Gaziosmanpaşa University, Department of Business Administration. Taşliçiftlik Yerleşkesi, 60250 Tokat, Turkey. E-mail: oktay.ozkan@ gop.edu.tr. ORCID: 0000-0001-9419-8115.
}

Boğaziçi Journal Review of Social, Economic and Administrative Studies, Vol. 34, no. 2 (2020), pp. 101-113, doi: 10.21773/boun.34.2.1 
$\mathrm{O}$ ne of the most frequently discussed topics in empirical finance literature is whether the returns of financial assets can be predicted with the help of information. The efficient markets hypothesis (EMH) of Fama (1970) asserts that prices fully reflect all available information and financial assets returns are purely unpredictable (Fama, 1970). In an efficient market, new information spreads very quickly and is reflected in asset prices without delay (Malkiel, 2003). Although the EMH asserts that asset prices are unpredictable, studies testing the validity of the EMH empirically have reported some anomalies (e.g., the weekend, momentum, disposition effects) that conflict with the foundation of the hypothesis. Besides this, the studies of some psychologists and experimental economists have exhibited many behavioral biases in human decision-making processes under uncertainty, including regret, loss aversion, overreaction, overconfidence, etc (Jiang and Li, 2020). These developments have led to the emergence of a new branch of finance called behavioral finance. The advocates of both the $\mathrm{EMH}$ and behavioral finance have never reached a truce, and there is still no consensus as to which school of thought is dominant.

Lo (2004) developed the adaptive markets hypothesis (AMH) to reconcile these two opposing schools of thought (the EMH and behavioral finance). According to Lo (2004), the $\mathrm{AMH}$ is a new version of the EMH, based on evolutionary principles. The AMH states that efficiency of financial markets is not an all-or-none condition but is a characteristic that varies continuously over time and across markets (Lim et al., 2013). The implications of the AMH are as follows: (1) risk-reward relationship and therefore the equity risk premium changes over time; (2) arbitrage opportunities may occur from time to time, contrary to the EMH; (3) investment strategies' performances are time-varying; (4) the only key to survival is innovation; (5) survival is the only objective that matters; (6) a final important implication of the AMH is that financial markets may depart from efficiency from time to time, through changing market conditions (e.g., crises, pandemics, bubbles, cycles, crashes) and institutional factors (Lo, 2004, 2005).

The implications of the AMH can be tested by tracking the degree of return predictability (or market efficiency) over time. If the degree of return predictability of a market varies over time, it can be concluded that the efficiency of this market is consistent with the implications of the AMH. Otherwise, it can be inferred that the efficiency of the relevant market is consistent with the implications of the EMH. In the existing literature, a large number of studies have reported that the efficiency of various financial markets is time-varying consistent with the implications of the AMH (see, for example, Lo, 2004; Lim et al., 2013; Popović et al., 2013; Ghazani and Araghi, 2014; Verheyden et al., 2015; Ito et al., 2016; Noda, 2016; Charles et al., 2017; Rahman et al., 2017; Chu et al., 2019; Jiang and Li, 2020; Noda, 2020). These studies report time-varying return predictability by examining only price movements. However, no study investigating return predictability using some return predictors within the AMH framework has been found. Therefore, the objective of this paper is to examine the evolution of the return predictability (or market efficiency) of stock markets and to fill this large gap in the existing literature by assessing whether the empirical findings are consistent with the implications of the AMH. This paper uses the novel wild bootstrap likelihood ratio (LR) test proposed by Kim and Shamsuddin (2020) with the rolling sub-sample windows to investigate whether the degree of stock market efficiency of Mexico, Indonesia, South Korea, and Turkey 
(MIST) countries varies with time as consistent with the AMH. ${ }^{1}$ More specifically, this paper focuses on whether the predictability degree of stock market returns with inflation and trading volume varies over time. After the wild bootstrap LR test is applied on monthly data from January 1993 to July 2020, it is found that returns of all MIST stock markets can be predicted with both inflation and trading volume in some periods. This result indicates that the degree of return predictability (or market efficiency) varies over time which is consistent with the implications of the $\mathrm{AMH}$, and that the $\mathrm{AMH}$ has better implications to explain the real market behavior compared to the EMP. Importantly though, results are robust against using other predictor variables such as exchange rate and realized volatility.

The contributions of this paper to the literature are at least four-fold. First, this paper is the first to investigate the degree of efficiency (or return predictability) of stock markets using return predictors within the AMH framework. Second, this paper uses a novel econometric model, the wild bootstrap LR test developed by Kim and Shamsuddin (2020), which is robust to the well-known features of the financial time series i.e., non-normality, small sample bias, endogeneity and conditional heteroskedasticity. Third, this paper demonstrates the time-varying predictability degree of stock market returns using four different predictor variables. Fourth, this paper shows the periods when stock markets deviate from market efficiency for each MIST country.

The remainder of this paper is structured as follows. Section 2 provides some information about the methodology used. Section 3 presents the characteristics of the data. The empirical results are reported and discussed in Section 4. Section 5 sets forth the results of a robustness test including other predictor variables. Finally, Section 6 concludes the paper.

\section{Methodology}

In this paper, the novel wild bootstrap likelihood ratio test of Kim and Shamsuddin (2020) is used to evaluate the time-varying degree of market efficiency for MIST countries. The wild bootstrap test is based on the LR test in a restricted vector autoregression (VAR) form of predictive regression. This test is robust to non-normality, small sample bias, endogeneity and conditional heteroskedasticity, all typical features of the financial time series (see Kim \& Shamsuddin, 2020 for details). The predictive regression model with inflation and trading volume treated as persistent predictors of stock returns can be written as:

$$
R_{t}=\alpha_{0}+\beta_{1} I N F_{t-1}+\beta_{2} V O L_{t-1}+\varepsilon_{t}
$$

where $R_{t}$ denotes stock returns, INF the inflation, and $V O L$ the trading volume. To take endogeneity into account, the predictors are expressed in the following manner:

$$
I N F_{t}=\alpha_{1}+\theta_{1} I N F_{t-1}+\gamma_{1 t}
$$

\footnotetext{
${ }^{1}$ In this paper, MIST countries are preferred for some reasons. First, these countries showed higher rate of economic growth than the developed countries, and increased their share in the world GDP and foreign direct investments. Second, MIST emerging economies were less affected by the global financial crisis and showed less depth of recession compared to the developed economies, making MIST financial markets more attractive for investors (Yarovaya and Lau, 2016). Third, these countries provide major investment opportunities. Fourth, MIST economies are seen the next tier of large emerging economies (Yang et al., 2015). Fifth, as the BRICS (Brazil, Russia, India, China and South Africa) economies have started to slow down, investment opportunities in the MIST countries have become more attractive based on expectations for high growth due to their favourable demographics and fast-paced economies (Afework et al., 2020; de Boyrie and Pavlova, 2016).
} 


$$
V O L_{t}=\alpha_{2}+\theta_{2} V O L_{t-1}+\gamma_{2 t}
$$

In Eqs. (1) to (3), it is assumed that $I N F$ and $V O L$ are weakly stationary, $\varepsilon_{t}$ and $\gamma_{1,2 t}$ are white noise error terms, the parameters $\beta s$ and $\theta s$ measure predictive ability and persistence of predictors, respectively. The null hypothesis that the predictor variables $\left(I N F_{t}\right.$ and $\left.V O L_{t}\right)$ do not have the ability to predict stock returns is formulated as $H_{0}: \beta_{i}=0$.

\section{Augmented regression method}

The augmented regression method (ARM) employed relies on the assumption that the error terms in Eqs. (1) to (3) are connected in the following manner: $\varepsilon_{t}=\emptyset \gamma_{1 t}+\emptyset \gamma_{2 t}+e_{t} \cdot \gamma_{1 t}, \gamma_{2 t}$ and $e_{t}$ are normally distributed and independent, with fixed variance and mean of zero.

To begin with, bias-adjusted estimations of Eqs. (2) and (3) are carried out as follows:

$$
\begin{aligned}
& I N F_{t}=\hat{a}_{1}^{c}+\hat{\theta}_{1}^{c} I N F_{t-1}+\gamma_{1 t}^{c} \\
& V O L_{t}=\hat{a}_{2}^{c}+\hat{\theta}_{2}^{c} V O L_{t-1}+\gamma_{2 t}^{c}
\end{aligned}
$$

Where $\hat{a}_{i}^{c}$ and $\hat{\theta}_{i}^{c}$ denote the bias-adjusted estimators for $\alpha_{i}$ and $\theta_{i}$ obtained via the asymptotic formulae of Stine and Shaman (1989), and $\gamma_{i t}^{c}$ represents the corresponding residual.

Eq. (1) is then further augmented in the following manner:

$$
R_{t}=\alpha_{0}+\beta_{1} I N F_{t-1}+\beta_{2} V O L_{t-1}+\emptyset \gamma_{1 t}^{a}+\emptyset \gamma_{2 t}^{a}+e_{t}
$$

In Eq. (6), the least squares (LS) estimators for $\beta_{i}$ are the bias-adjusted ARM estimators. Estimations carried out with ARM estimators display better small sample properties in comparison to conventional least squares estimations (Amihud, Hurvich \& Wang, 2010; Kim, 2014b; Kim \& Shamsuddin, 2020).

\section{A bootstrap LR test}

Eqs. (1) to (3) are treated as a restricted VAR. The estimated generalized least squares (EGLS) method is used in place of LS to estimate the restricted VAR. This is because LS is not as efficient as EGLS and also does not deal with the problem of endogeneity that often arises from contemporaneous correlations between the error terms. The null hypothesis, $H_{0}: \beta_{i}=0$, implying that the inflation and trading volume variables do not have the ability to predict stock returns, is tested with the LR test specified as follows:

$$
L R=T\left[\log \left(\operatorname{det}\left(\Sigma\left(H_{0}\right)\right)\right)-\log \left(\operatorname{det}\left(\Sigma\left(H_{1}\right)\right)\right)\right]
$$

Here, $T$ refers to the sample size, $\operatorname{det}()$ stands for the matrix determinant, while $\Sigma\left(H_{i}\right)$ represents the EGLS residual covariance matrix for $H_{i}(i=0$ or 1$)$. To guard against small sample bias which the LR test is prone to, a bootstrap alternative that is robust to this problem is employed. For a sample $\left\{\left(R_{t}, I N F_{t}, V O L_{t}\right)\right\}_{t=1}^{T}$, the bootstrap test is performed in 3 stages as follows: 
Stage 1: In this stage, parameters are estimated through EGLS under $H_{0}: \beta_{1}=0$ in Eqs. (1) to (3). The restricted parameter estimators are given as: $\hat{\alpha}_{0}, \hat{\alpha}_{1}, \hat{\alpha}_{2}, 0, \hat{\beta}_{2}, \hat{\theta}_{1}, \hat{\theta}_{2}$, while $\hat{\varepsilon}_{t}, \hat{\gamma}_{1 t}, \hat{\gamma}_{2 t}$ represent the residuals under $H_{0} \cdot{ }^{2}$

Stage 2: Artificial data generation through residual resampling under $H_{0}$ is carried out as follows:

$$
\begin{aligned}
& R_{t}^{*}=\hat{\alpha}_{0}+\hat{\beta}_{2} V O L_{t-1}^{*}+\hat{\varepsilon}_{t}^{*} \\
& I N F_{t}^{*}=\hat{\alpha}_{1}+\hat{\theta}_{1} I N F_{t-1}^{*}+\hat{\gamma}_{1 t}^{*} \\
& V O L_{t}^{*}=\hat{\alpha}_{2}+\hat{\theta}_{2} V O L_{t-1}^{*}+\hat{\gamma}_{2 t}^{*}
\end{aligned}
$$

Where $\left(\hat{\varepsilon}_{t}^{*}, \hat{\gamma}_{1 t}^{*}, \hat{\gamma}_{2 t}^{*}\right)$ represents a random resample obtained from $\left\{\left(\hat{\varepsilon}_{t}, \hat{\gamma}_{1 t}, \hat{\gamma}_{2 t}\right)\right\}_{t=1}^{T}$. Thus, in this stage, $\left\{\left(R_{t}^{*}, I N F_{t}^{*}, V O L_{t}^{*}\right)\right\}_{t=1}^{T}$ is generated recursively from the resampled residuals in a process that takes $R_{1}, I N F_{1}, V O L_{1}$ as the starting values.

Stage 3: As a final step, the bootstrap LR test statistic is calculated in this stage using the formula:

$$
L R^{*}=T\left[\log \left(\operatorname{det}\left(\Sigma^{*}\left(H_{0}\right)\right)\right)-\log \left(\operatorname{det}\left(\Sigma^{*}\left(H_{1}\right)\right)\right)\right]
$$

Here, $\Sigma^{*}\left(H_{i}\right)$ stands for the EGLS residual covariance matrix obtained from $\left\{\left(R_{t}^{*}, I N F_{t}^{*}, V O L_{t}^{*}\right)\right\}_{t=1}^{T}$ under $H_{i}(i=0$ or 1$)$.

The second and third stages are repeated $G$ times to generate the bootstrap distribution $\left\{L R^{*}(i)\right\}_{i=1}^{G}$. Bootstrap p-values are then generated as the part of $\left\{L R^{*}(i)\right\}_{i=1}^{G}$ higher than the LR value calculated in eq. (7). The $H_{0}$ is rejected at a particular significance level $(\propto)$ if p-value obtained is lower than $\propto$. The Mammen (1993) wild bootstrap is selected for its ability to strengthen the bootstrap LR test against small sample properties and heteroskedasticity.

\section{Data}

This part of the paper contains information about the dependent (predicted) and independent (predictor) variables used in the analyses.

\section{Dependent variables and descriptive statistics}

In this paper, returns of Mexico, Indonesia, South Korea, and Turkey (MIST) countries' major stock market indices (MXX, JKSE, KOSPI, and BIST 100, respectively) are used as dependent (predicted) variables. All return series are obtained from www.investing.com as a monthly frequency for the period from January 1993 to July 2020 (331 observations). ${ }^{3}$ Table 1 reports the descriptive statistics of return series.

From the table, it is observed that MIST stock market indices have positive average return. Judging from the mean values, the KOSPI index of South Korea has the lowest average return with $0.362 \%$, while the BIST 100 index of Turkey has the highest average return with $2.340 \%$. In terms of standard deviation, return volatility for the MXX index of Mexico is the smallest among the MIST stock market indices, $6.638 \%$, while that for the BIST index of Turkey is $12.069 \%$, which is the largest among the MIST stock market indices. The stock

\footnotetext{
${ }^{2}$ Note that $\hat{\beta}_{1}=0$ under $H_{0}$.

${ }^{3}$ The beginning of the sample period is dictated by the volume data availability of the JKSE index of Indonesia.
} 
market indices of Mexico and Indonesia are negatively skewed, while stock market indices of South Korea and Turkey are positively skewed. The return distributions of all stock market indices have excess kurtosis. Both skewness and kurtosis results indicate that all return series used in the paper are not normally distributed. Furthermore, the non-normality of the return series is also confirmed by the strong rejection of the Jarque-Bera statistic at the $1 \%$ level. The KPSS test results indicate that all dependent variables (return series) are stationary during the sample period.

Table 1 Descriptive statistics

\begin{tabular}{llccc}
\hline & \multicolumn{4}{c}{ Dependent variables } \\
\cline { 2 - 5 } & MXX & JKSE & KOSPI & BIST 100 \\
\hline Mean & 0.920 & 0.886 & 0.362 & 2.340 \\
Maximum & 17.661 & 25.019 & 41.062 & 58.666 \\
Minimum & -34.981 & -37.856 & -31.810 & -49.483 \\
Std. dev. & 6.638 & 7.516 & 7.523 & 12.069 \\
Skewness & -0.851 & -1.098 & 0.203 & 0.309 \\
Kurtosis & 6.519 & 8.239 & 6.964 & 6.370 \\
Jarque-Bera & $210.783^{* * *}$ & $445.182 * * *$ & $219.009 * * *$ & $161.900^{* * *}$ \\
KPSS & 0.296 & 0.084 & 0.040 & 0.094 \\
\hline
\end{tabular}

Note: $* * *$ denote statistical significance at the $1 \%$ level. KPSS indicates the Kwiatkowski, Phillips, Schmidt, \& Shin test (1992) for stationarity.

\section{Predictor variables, persistence of predictor variables and contemporaneous correlation between error terms}

In this paper, two variables among the commonly used predictors of returns in empirical finance literature are used as return predictors, namely, inflation (see for example, Campbell and Vuolteenaho, 2004; Patra and Poshakwale, 2006; Hasan, 2008; Welch and Goyal, 2008; Rapach and Zhou, 2013) and trading volume (see for example, Chen et al., 2001; Statman et al., 2006; Chuang et al., 2009; Chen, 2012; Gupta et al., 2018a). Following the works of Jeffe and Mandelker (1976), Welch and Goyal (2008) and Rapach and Zhou (2013), consumer price index (CPI) is used as a measure of inflation. Volume series are obtained from www.investing.com, while inflation (CPI) series are downloaded from the database of the International Monetary Fund. The persistence property of predictor variables is particularly important for determining the finite sample performance of predictive test statistics (Ang and Bekaert, 2007). To assess the persistence of predictor variables, the magnitude of first-order autoregressive (AR(1)) coefficient, and the KPSS test for the null hypothesis of stationarity (Kwiatkowski et al., 1992) are used. The results in Table 2 demonstrate that the null hypothesis of stationarity is rejected for all predictors i.e., predictor variables are non-stationary during the sample period. It is also seen that AR(1) coefficients of predictors are very close to 1 . Both KPSS test statistics and AR(1) coefficients clearly show that predictors are highly persistent.

The contemporaneous correlation results in Table 2 indicate that some of the error terms are correlated. The properties of predictor variables (such as, a high degree of persistence, and contemporaneous correlations among the error terms) justify use of the EGLS estimator rather than the LS estimator. 
Table 2

Persistence measures and contemporaneous correlation

\begin{tabular}{|c|c|c|c|c|c|c|c|c|}
\hline & \multicolumn{8}{|c|}{ Independent variables } \\
\hline & \multicolumn{2}{|c|}{ Mexico } & \multicolumn{2}{|c|}{ Indonesia } & \multicolumn{2}{|c|}{ South Korea } & \multicolumn{2}{|c|}{ Turkey } \\
\hline & INF & VOL & INF & VOL & INF & VOL & INF & VOL \\
\hline \multicolumn{9}{|c|}{ Persistence measures } \\
\hline KPSS & $2.120 * * *$ & $1.688 * * *$ & $2.164 * * *$ & $1.917 * * *$ & $2.165 * * *$ & $0.783 * * *$ & $2.060 * * *$ & $1.841 * * *$ \\
\hline $\begin{array}{l}\mathrm{AR}(1) \\
\text { coefficient }\end{array}$ & $0.999 * * *$ & $0.865 * * *$ & $0.999 * * *$ & $0.876^{* * *}$ & $0.997 * * *$ & $0.839 * * *$ & $0.999 * * *$ & $0.999 * * *$ \\
\hline \multicolumn{9}{|c|}{ Contemporaneous correlation } \\
\hline & 0.026 & -0.033 & $-0.091 *$ & $0.116 * *$ & 0.038 & $0.158 * * *$ & 0.015 & $0.161 * * *$ \\
\hline
\end{tabular}

Note: $* * * * *$ and $*$ denote statistical significance at the $1 \%, 5 \%$ and $10 \%$ levels, respectively. KPSS indicates the Kwiatkowski, Phillips, Schmidt, \& Shin test (1992) for stationarity. AR(1) denotes first-order autoregressive.

\section{Empirical Results}

In this paper, the wild bootstrap LR test is applied with the rolling sub-sample windows method to investigate time-varying degree of return predictability. ${ }^{4,5}$ The rolling sub-sample windows method enables the detection of the time-varying degree of return predictability (or market efficiency). Also, the rolling sub-sample windows method adequately prevents data snooping bias (Hsu and Kuan, 2005) and is robust to possible structural instabilities in the time series (Lazăr et al., 2012). The length of the sub-sample window is determined as 5 years (60 monthly observations), which is adequate for capturing the impacts of variations in market conditions (Charles et al., 2017). ${ }^{6}$ This sub-sample window length is also sufficient to ensure the desirable size and power properties of the test used (Charles et al., 2011). In this paper, the first subsample period spans from January 1993 to December 1997. After the wild bootstrap LR test is applied on the first sub-sample period, the window moves forward by one month and the test is reapplied. This process is continued till the end of the sample period, and the wild bootstrap LR test p-values for each sub-sample (a total of 272 sub-samples) are obtained as a measure of time-varying return predictability. This process enables episodes of high degree of return predictability (statistically significant) to be recognized.

Figure 1 plots the $\mathrm{p}$ values of the wild bootstrap LR test for $H_{0}: \beta_{i}=0$ for both predictors. The p-value in the shaded area indicates the rejection of the null hypothesis of no predictability at $10 \%$ level of significance i.e., returns are predicted with the relevant predictor in that period and there is no market efficiency. Graphical plots in Figure 1 show that the null hypothesis of no return predictability is rejected in some periods for both predictors. In other words, the predictive ability of both inflation and trading volume on returns is time-varying. The stock market of Mexico is inefficient from mid-2001 to late 2001, late 2004 to early 2007, late 2010 to early 2014, and in 2020. The inefficiency of the stock market of Indonesia is seen from late 2004 to mid-2005, late 2008 to late 2013, late 2015 to mid-2016, and in March 2020. In South Korea, stock market inefficiency is seen from late 1997 to early 2000, late 2008 to mid-2010, late 2013 to early 2014 , late 2017 to late 2018 , and mid-2019 to early 2020. Finally, the stock market of Turkey is inefficient from mid-2000 to late 2000, mid-2003 to early 2004, mid-2007 to late 2007, mid-2009 to late 2011, late 2013 to early 2014, and late 2019 to early

\footnotetext{
${ }^{4}$ The choice for the rolling sub-sample windows method to investigate the AMH follows naturally from the concept of time-varying efficiency.

5 The R package "VAR.etp" developed by Kim (2014a) is used for the analysis.

${ }^{6}$ Since Kim et al. (2011), Charles et al. (2017), Khuntia and Pattanayak (2018), and Kim and Shamsuddin (2020) empirically show that the test results are not sensitive to the different choices of window length, different window lengths are not used in the paper.
} 
2020. In sum, the findings of this study verify that the degree of market efficiency of all MIST emerging stock markets varies over time, in line with the implications of the AMH.

Figure 1 The wild bootstrap LR test p-values. Shaded area represents significant p-values at the $10 \%$ significance level
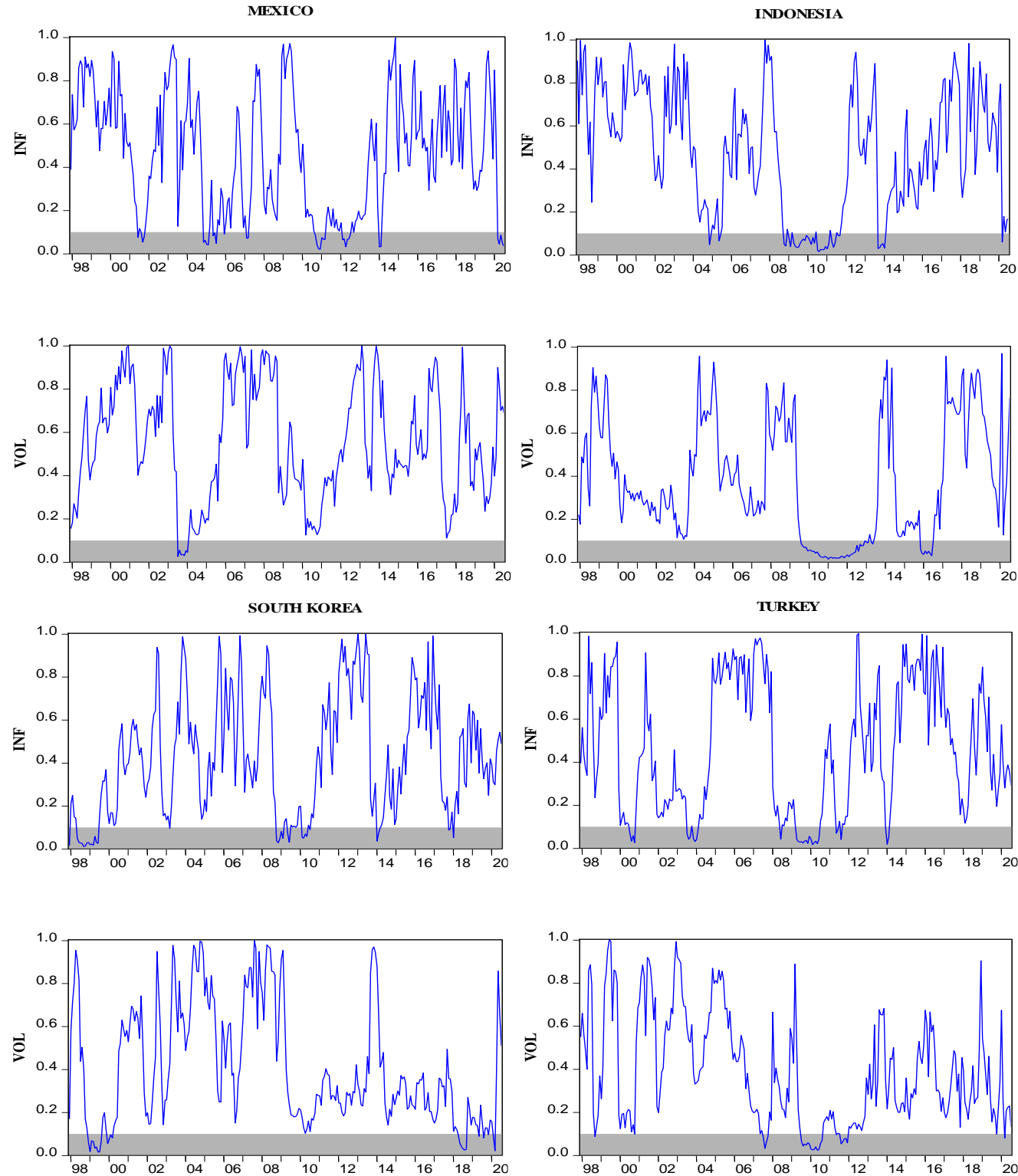

\section{Robustness Test}

The main findings of the paper, described in Section 4, are based on two predictors such as inflation and trading volume. Therefore, one possible criticism of the results thus far is that the results are sensitive to the choice of predictors. In this section, a check of this is attempted. To do so, analyses are repeated using two different predictors commonly used in empirical finance literature as return predictors, namely, exchange rate vis-a-vis the US dollar (ER) (see for example, Nieh and Lee, 2001; Lin, 2012; Tsai, 2012; Inci and Lee, 2014; Wong, 2017; Bai and Koong, 2018) and realized volatility (RV) (see for example, Welch and Goyal, 2008; Bali and Hovakimian, 2009; Ahoniemi and Lanne, 2013; Narayan and Bannigidadmath, 2015; Devpura 
et al., 2018; Dai and Zhou, 2020). ${ }^{7}$ Following the paper of Gupta et al. (2018b), monthly RV series for each MIST country are computed as sums of daily squared returns over a month. Both ER and daily return series are gathered from www.investing.com.

The persistence properties and contemporaneous correlations of these predictor variables are reported in Table 3. In line with the results for INF and VOL, the results indicate that both ER and RV are also highly persistent and error terms are correlated.

Table $3 \quad$ Persistence measures and contemporaneous correlation

\begin{tabular}{|c|c|c|c|c|c|c|c|c|}
\hline & \multicolumn{8}{|c|}{ Independent variables } \\
\hline & \multicolumn{2}{|c|}{ Mexico } & \multicolumn{2}{|c|}{ Indonesia } & \multicolumn{2}{|c|}{ South Korea } & \multicolumn{2}{|c|}{ Turkey } \\
\hline & RV & ER & $\mathrm{RV}$ & ER & RV & ER & $\mathrm{RV}$ & ER \\
\hline \multicolumn{9}{|c|}{ Persistence measures } \\
\hline KPSS & $0.896^{* * *}$ & $1.313 * * *$ & 0.317 & $1.274 * * *$ & $0.649 * *$ & $0.627 * *$ & $1.410 * * *$ & $0.879 * * *$ \\
\hline $\begin{array}{l}\mathrm{AR}(1) \\
\text { coefficient }\end{array}$ & $0.511 * * *$ & $0.977 * * *$ & $0.534 * * *$ & $0.988 * * *$ & $0.654 * * *$ & $0.978 * * *$ & $0.565 * * *$ & $0.946^{* * *}$ \\
\hline \multicolumn{9}{|c|}{ Contemporaneous correlation } \\
\hline & $-0.304 * * *$ & $0.236 * * *$ & $-0.301 * * *$ & $0.171 * * *$ & $-0.324 * * *$ & $0.345^{* * *}$ & -0.064 & 0.086 \\
\hline
\end{tabular}

Note: $* * * * *$ and $*$ denote statistical significance at the $1 \%, 5 \%$ and $10 \%$ levels, respectively. KPSS indicates the Kwiatkowski, Phillips, Schmidt, \& Shin test (1992) for stationarity. AR(1) denotes first-order autoregressive.

The $\mathrm{p}$ values of the wild bootstrap LR test for $H_{0}: \beta_{i}=0$ for both ER and RV are plotted in Figure 2. Graphical plots in Figure 2 demonstrates that the null hypothesis of no return predictability is rejected in some periods for both predictors i.e., the predictive ability of ER and RV on returns is time-varying. These findings also verify that the degree of market efficiency of all MIST emerging stock markets varies over time, in line with the implications of the AMH.

Figure 2 The wild bootstrap LR test p-values. Shaded area represents significant p-values at the $10 \%$ significance level
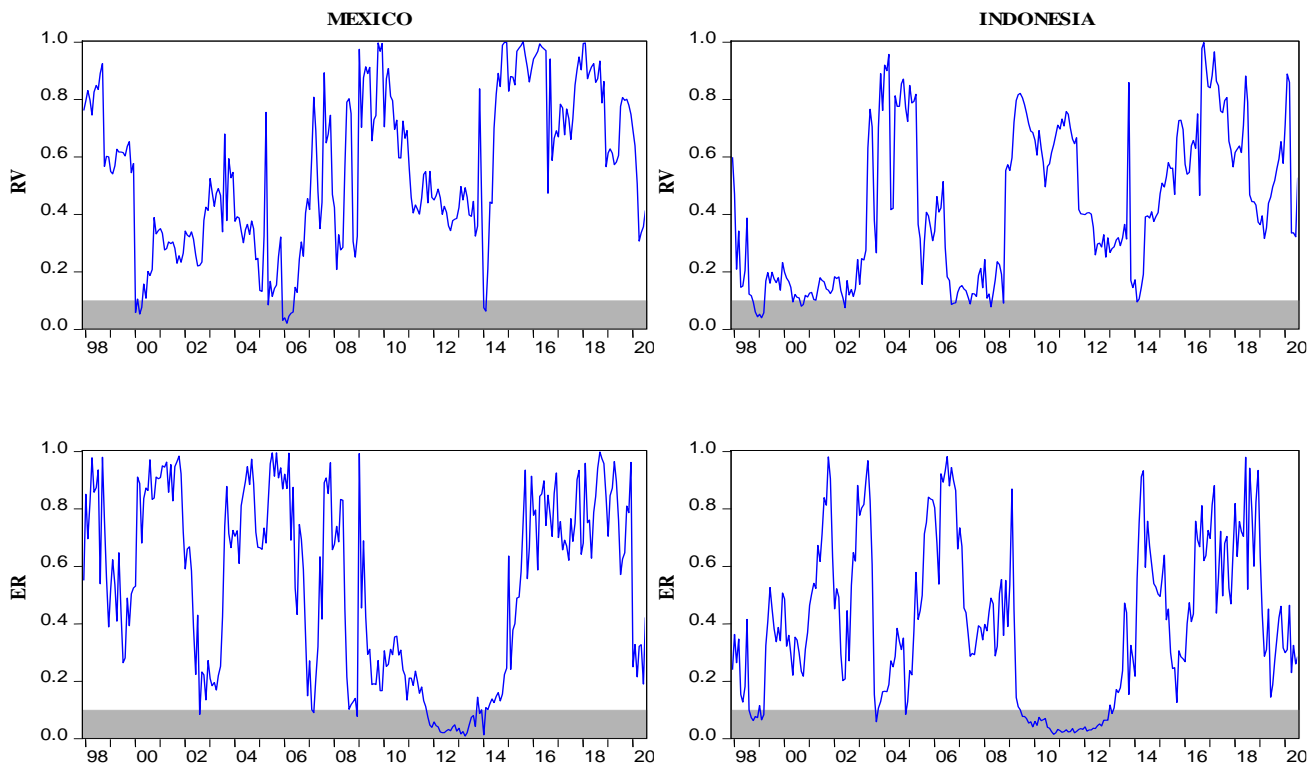

\footnotetext{
${ }^{7}$ Note that although there are many return predictors in empirical finance literature, predictors used in this study are dictated by data availability for all MIST countries over the period from January 1993 to July 2020.
} 

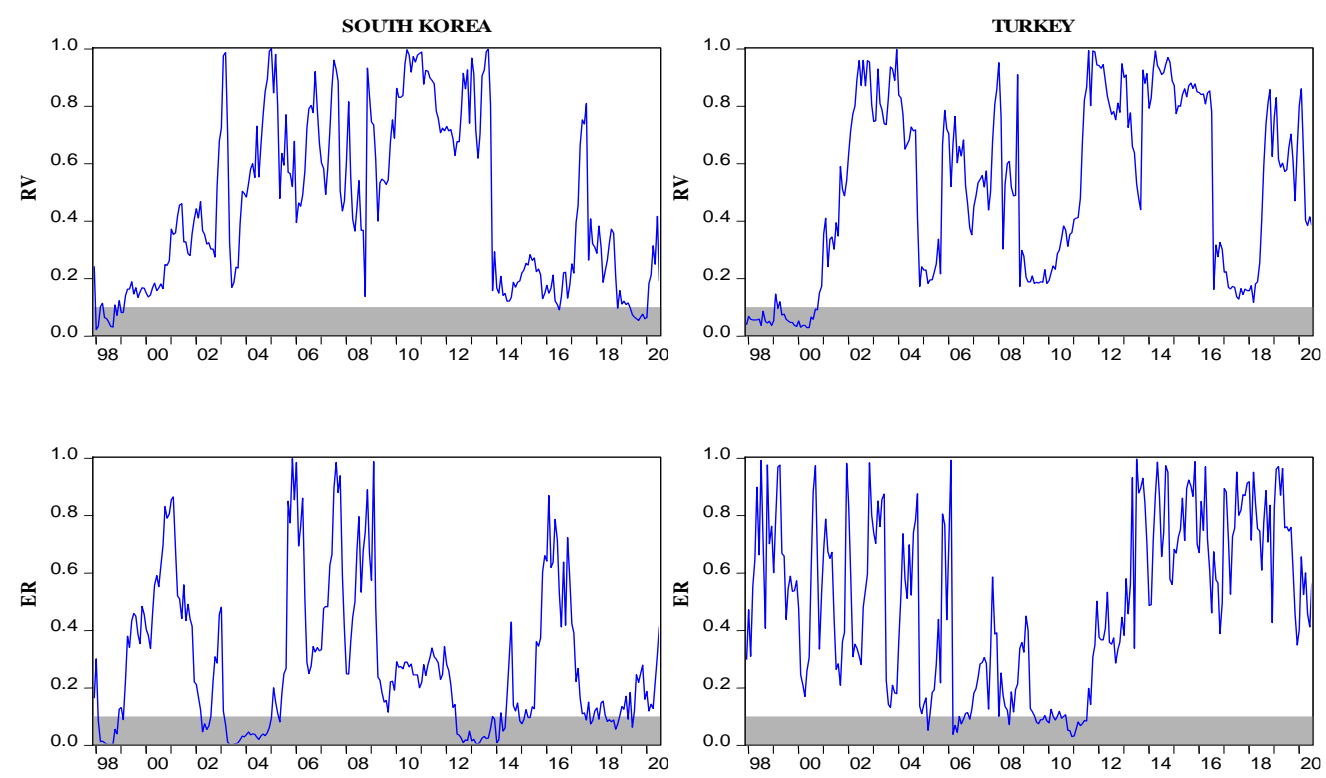

\section{Conclusion}

In this paper, time-varying degree of return predictability (or market efficiency) of MIST emerging stock markets has been examined and it has been evaluated whether the findings are consistent with the implications of the AMH. To realize this, the time-varying predictability degree of MIST stock markets returns with inflation and trading volume have been analyzed using the wild bootstrap LR test of Kim and Shamsuddin (2020) with the rolling sub-sample windows method. The analysis carried out on the monthly data covers the period from January 1993 to July 2020. Results demonstrate that the predictability degree of all MIST stock markets returns with both inflation and trading volume is time-varying. In other words, the degree of market efficiency of MIST stock markets varies over time consistent with the implications of the AMH. These results are robust against using different predictor variables such as exchange rate and realized volatility which exhibit similar patterns. Predictability of MIST stock markets returns using inflation, trading volume, exchange rate and realized volatility in some periods can be interpreted as a possibility of obtaining abnormal profits and beating the market. Therefore, it can have important policy implications for participants as they will have the opportunity to make abnormal profits and beat the market in MIST stock markets by examining inflation and trading volume values of MIST countries. These markets have become more speculative through the predictable patterns in stock prices, which make it even more important to regulate and control the stock markets. This paper also provides important information to academics in terms of revealing a new field of research related to the Adaptive Markets Hypothesis. 


\section{References}

Afework, B., Hanania, J., Stenhouse, K., \& Donev, J. (2020). Energy education - N11 countries. Retrieved from https://energyeducation.ca/encyclopedia/N11_countries.

Ahoniemi, K., \& Lanne, M. (2013). Overnight stock returns and realized volatility. International Journal of Forecasting, 29(4), 592-604.

Amihud, Y., Hurvich, C. M., \& Wang, Y. (2010). Predictive regression with order-p autoregressive predictors. Journal of Empirical Finance, 17(3), 513-525.

Ang, A., \& Bekaert, G. (2007). Stock return predictability: Is it there? Review of Financial Studies, 20, 651-707.

Bai, S., \& Koong, K. S. (2018). Oil prices, stock returns, and exchange rates: Empirical evidence from China and the United States. The North American Journal of Economics and Finance, 44, 12-33.

Bali, T. G., \& Hovakimian, A. (2009). Volatility Spreads and Expected Stock Returns. Management Science, 55(11), 1797-1812.

Campbell, J. Y., \& Vuolteenaho,T. (2004). Inflation illusion and stock prices. American Economic Review, 94, 19-23.

Charles, A., Darné, O., \& Kim, J. H. (2011). Small sample properties of alternative tests for martingale difference hypothesis. Economics Letters, 110, 151-154.

Charles, A., Darné, O., \& Kim, J. H. (2017). Adaptive markets hypothesis for Islamic stock indices: Evidence from Dow Jones size and sector-indices. International Economics, $151,100-112$.

Chen, G.-M., Firth, M., \& Rui, O. M. (2001). The dynamic relation between stock returns, trading volume, and volatility. The Financial Review, 38, 153-174.

Chen, S.-S. (2012). Revisiting the empirical linkages between stock returns and trading volume. Journal of Banking \& Finance, 36(6), 1781-1788.

Chuang, C.-C., Kuan, C.-M., Lin, H.-Y. (2009). Causality in quantiles and dynamic stock return-volume relations. Journal of Banking \& Finance, 33(7), 1351-1360.

Dai, Z., \& Zhou, H. (2020). Prediction of stock returns: Sum-of-the-parts method and economic constraint method. Sustainability, 12(2), 541.

De Boyrie, M. E., \& Pavlova, I. (2016). Dynamic interdependence of sovereign credit default swaps in BRICS and MIST countries. Applied Economics, 48(7), 563-575.

Devpura, N., Narayan, P. K., \& Sharma, S. S. (2018). Is stock return predictability timevarying? Journal of International Financial Markets, Institutions \& Money, 52, 152172.

Fama, E. F. (1970). Efficient capital markets: A review of theory and empirical work. Journal of Finance, 25, 383-417.

Ghazani, M. M., \& Araghi, M. K. (2014). Evaluation of the adaptive market hypothesis as an evolutionary perspective on market efficiency: Evidence from the Tehran stock exchange. Research in International Business and Finance, 32, 50-59.

Gupta, R., Das, D., Hasim, H., \& Tiwari, A. K. (2018a). The dynamic relationship between stock returns and trading volume revisited: A MODWT-VAR approach. Finance Research Letters, 27, 91-98. 
Gupta, R., Pierdzioch, C., Selmi, R., \& Wohar, M. E. (2018b). Does partisan conflict predict a reduction in US stock market (realized) volatility? Evidence from a quantile-on-quantile regression model. The North American Journal of Economics and Finance, 43, 87-96.

Hasan, M. S. (2008) Stock returns, inflation and interest rates in the United Kingdom. The European Journal of Finance, 14(8), 687-699.

Hsu, P.-H., \& Kuan, C.-M. (2005). Re-examining profitability of technical analysis with data snooping check. Journal of Financial Econometrics, 3(4), 606-628.

Inci, A. C., \& Lee, B. S. (2014). Dynamic Relations between Stock Returns and Exchange Rate Changes. European Financial Management, 20(1), 71-106.

Ito, M., Noda, A., \& Wada, T. (2016). The evolution of stock market efficiency in the US: a non-Bayesian time-varying model approach. Applied Economics, 48(7), 621-635.

Jaffe, J. F., \& Mandelker, G. (1976). The "Fisher effect" for risky assets: an empirical investigation. Journal of Finance, 31, 447-58.

Jiang, J., \& Li, H. (2020). A new measure for market efficiency and its application. Finance Research Letters, 34. Article no. 101235.

Khuntia, S., \& Pattanayak, J. K. (2018). Adaptive market hypothesis and evolving predictability of bitcoin. Economics Letters, 167, 26-28.

Kim J. H. (2014a). VAR.etp: VAR modelling: estimation, testing, and prediction. R package version 0.7. https://CRAN.R-project.org/package=VAR.etp.

Kim, J. H. (2014b). Predictive regression: An improved augmented regression method. Journal of Empirical Finance, 26, 13-25.

Kim, J. H., \& Shamsuddin, A. (2020). A bootstrap test for predictability of asset returns. Finance Research Letters, 35, 101289.

Kim, J. H., Shamsuddin, A., \& Lim, K-P. (2011). Stock return predictability and the adaptive markets hypothesis: Evidence from century-long U.S. data. Journal of Empirical Finance, 18, 868-879.

Kwiatkowski, D., Phillips, P. C., Schmidt, P., \& Shin, Y. (1992). Testing the null hypothesis of stationarity against the alternative of a unit root: How sure are we that economic time series have a unit root? Journal of Econometrics, 54, 159-178.

Lazăr, D., Todea, A., \& Filip, D. (2012). Martingale difference hypothesis and financial crisis: Empirical evidence from European emerging foreign exchange markets. Economic Systems, 36(3), 338-350.

Lim, K-P., Luo, W., \& Kim, J. H. (2013). Are US stock index returns predictable? Evidence from automatic autocorrelation-based tests. Applied Economics, 45(8), 953-962.

Lin, C-H. (2012). The comovement between exchange rates and stock prices in the Asian emerging markets. International Review of Economics \& Finance, 22(1), 161-172.

Lo, A. W. (2004). The adaptive markets hypothesis. The Journal of Portfolio Management, 30(5), 15-29.

Lo, A. W. (2005). Reconciling efficient markets with behavioral finance: The adaptive markets hypothesis. Journal of Investment Consulting, 7(2), 21-44.

Malkiel, B. G. (2003). The Efficient Market Hypothesis and its critics. Journal of Economic Perspectives, 17(1), 59-82. 
Mammen, E. (1993). Bootstrap and wild bootstrap for high dimensional linear models. The Annals of Statistics, 21(1), 255-285.

Narayan, P. K., \& Bannigidadmath, D. (2015). Are Indian stock returns predictable? Journal of Banking \& Finance, 58, 506-531.

Nieh, C-C., \& Lee, C-F. (2001). Dynamic relationship between stock prices and exchange rates for G-7 countries. The Quarterly Review of Economics and Finance, 41(4), 477-490.

Noda, A. (2016). A test of the adaptive market hypothesis using a time-varying AR model in Japan. Finance Research Letters, 17, 66-71.

Noda, A. (2020). On the evolution of cryptocurrency market efficiency. Applied Economics Letters, In press. Retrieved from https://doi.org/10.1080/13504851.2020.1758617.

Patra, T., \& Poshakwale, S. (2006). Economic variables and stock market returns: evidence from the Athens stock exchange. Applied Financial Economics, 16, 993-1005.

Popović, S., Mugoša, A., \& Đurović, A. (2013) Adaptive markets hypothesis: Empirical evidence from Montenegro equity market. Economic Research-Ekonomska Istraživanja, 26(3), 31-46.

Rahman, L., Lee, D., \& Shamsuddin, A. (2017). Time-varying return predictability in South Asian equity markets. International Review of Economics and Finance, 48, 179-200.

Rapach, D., \& Zhou, G. (2013). Forecasting stock returns. In: Elliott, Graham, Timmermann, Allan (Eds.), Handbook of Economic Forecasting vol. 2. Elsevier, Amsterdam.

Statman, M., Thorley, S., \& Vorkink, K. (2006). Investor overconfidence and trading volume. The Review of Financial Studies. 19(4), 1531-1565.

Stine, R. A., \& Shaman, P. (1989). A fixed point characterization for bias of autoregressive estimators. Annals of Statistics, 17(3), 1275-1284.

Tsai, I-C. (2012). The relationship between stock price index and exchange rate in Asian markets: A quantile regression approach. Journal of International Financial Markets, Institutions and Money, 22(3), 609-621.

Verheyden, T., De Moor, L., \& den Bossche, F. V. (2015). Towards a new framework on efficient markets. Research in International Business and Finance, 34, 294-308.

Welch, I., \& Goyal, A. (2008). A comprehensive look at the empirical performance of equity premium prediction. The Review of Financial Studies, 21(4), 1455-1508.

Wong, H. T. (2017). Real exchange rate returns and real stock price returns. International Review of Economics \& Finance, 49, 340-352.

Yang, G. J-A., Lee, C., \& Lee, C-H. (2015). Random walk in the MIST. Journal of Asia-Pacific Business, 16(2), 92-104.

Yarovaya, L., \& Lau, M. C. K. (2016). Stock market comovements around the Global FinancialCrisis: Evidence from the UK, BRICS and MIST markets. Research in International Business and Finance, 37, 605-619. 